\title{
Concurrent and Longitudinal Relationships Between Development in Graphic, Language and Symbolic Play Domains from the Fourth to the Fifth Year
}

\author{
Julie Kirkham ${ }^{\mathrm{a}, *}$, Andrew Stewart ${ }^{\mathrm{b}}$ and Evan Kidd \\ ${ }^{a}$ Department of Psychology, University of Chester, Chester, UK \\ ${ }^{\mathrm{b}}$ Department of Psychological Sciences, University of Manchester, Manchester, UK \\ ${ }^{\mathrm{c} D e p a r t m e n t}$ of Psychological Sciences, Australian National University, Canberra, \\ Australia
}

This research investigated the developing inter-relationships between language, graphic symbolism and symbolic play both concurrently and longitudinally from the fourth to the fifth year of childhood. Sixty children $(n=60)$ aged between 3 and 4 years completed multiple assessments of language and assessments of graphic symbolism, symbolic play and non-verbal intelligence. A year later, 31 children $(n=31)$ were re-tested using the same assessments. The findings revealed that skills within each symbolic domain were inter-related during the fourth year, appearing to develop in a domain-general type fashion based upon a common underlying symbolic mechanism. However, between the fourth and the fifth years, only language had predictive validity, suggesting a shift towards the verbal mediation of symbolic play and graphic symbolism as language becomes progressively internalized (Vygotsky, 1962, 1978). Copyright (C) 2012 John Wiley \& Sons, Ltd.

Key words: graphic symbolism; symbolic play; language

Language, symbolic play and drawing are three important systems of symbolic representation that develop during early childhood. Although much research has focused upon the acquisition of language (Tomasello, 1999), the development of non-verbal symbolic systems has received comparatively little attention despite sharing important developmental, functional and structural attributes (Braswell, 2006). Problems of definition and measurement have traditionally

*Correspondence to: Dr Julie A. Kirkham, Department of Psychology, University of Chester,

Parkgate Road, Chester CH1 4BJ, UK. E-mail: j.kirkham@chester.ac.uk 
discouraged researchers from comparing development across different symbolic domains (Bornstein \& Tamis-LeMonda, 1995). However, identifying crossdomain developmental trajectories has important implications for understanding both typical and atypical developments (Karmiloff-Smith, 2009, 2011). The present research aimed to investigate the developing inter-relationships between the symbolic domains of language, symbolic play and graphic symbolism both concurrently during the fourth year and longitudinally between the fourth and the fifth years.

The relationship between language and other areas of cognition is of central importance to developmental theory and is encapsulated in the crucial debate concerning the domain generality or specificity of cognitive functioning (D'Souza \& Karmiloff-Smith, 2011; Stein \& Stanford, 2008). Such accounts vary in the extent to which language is viewed as dependent upon, or integrated with, other aspects of cognition. Domain-specific, nativist accounts propose a structure of the mind in which information is stored and processed by separate modules operating in specialized ways (e.g. Pinker, 1997). Within this account, cognitive change occurs separately and at different rates within different domains of knowledge and arises from the operation of many distinct, specific mental processes (Barrett \& Kurzban, 2006). Linguistic representations in particular are viewed as autonomous and formulated independently of any other cognitive system (Chomsky, 1957).

In contrast, a domain-general view of development (e.g. Piaget, 1952) argues that there are cognitive processes that operate across different areas of knowledge in similar ways and at similar rates. Thus, domain-general learning can be a process that results in fundamental stage-like change for both linguistic and non-linguistic cognition (Karmiloff-Smith, 1992). A major tenet of Piaget's work is that cognition develops prior to, and is the basis upon which, language develops, with language acquisition therefore based upon a number of cognitive prerequisites, such as understanding of categories (Gopnick \& Meltzoff, 1992). To Piaget, it is the child's accomplishment of abstract mental representation at the conclusion of the sensorimotor period that facilitates a domain-general shift in cognition, facilitated by the processes of assimilation, accommodation and equilibration. The achievement of abstract thought is therefore posited as the common internal process through which meaning is expressed in all symbolic systems, although development of additional skills (such as visual memory, vocal and motor control) are also required (McCune, 2008). Accordingly, symbolic development in a number of different domains is proposed to occur relatively simultaneously, with language regarded as but one reflection of a general shift in cognitive competence.

The minimal role that Piaget (1952) accorded language in the development of cognition has been opposed by Vygotskian-inspired socio-cultural theories of development (Vygotsky, 1962, 1978). Vygotsky argued that intellectual functioning is semiotically mediated by the symbol systems that a community uses. Natural language, in particular, is seen as playing a mediating, causal role in transforming external environmental inputs into internal, psychological knowledge (Fernyhough, 2008). Like Piaget, Vygotsky viewed the symbolic function as emerging towards the end of the second year, when infants achieve the naming insight. However, to Vygotsky, the representational function does not emerge entirely from cognition but from the integration of early speech and non-verbal systems. After such integration, language is posited to vastly augment cognition through its gradual internalization to become private speech around the fourth to the fifth year. Thus, although Vygotsky considered the symbolic function to allow a domain-general change in the child's cognitive abilities, language has a fundamental role in and is not dependent upon this change. Furthermore, of all 
collective symbolic activities, language is perceived as being the most important, developing prior to, and providing a scaffolding base for, other symbolic systems (see also Nelson, 2007).

Vygotsky's emphasis on the importance of language is also central to the cultural learning approach of Tomasello and associates (e.g. Carpenter, Nagell, \& Tomasello, 1998; Tomasello, 2003), in which language is viewed as developing from, and acquired as, a joint attentional activity to share and direct attention with others. This is a dialectical process, with linguistic ability posited to emerge from a succession of increasingly complex attentional behaviours, progressing from simple gaze following, to imitation, pointing and declarative gestures. The eventual dyadic and triadic nature of such behaviours is thought to allow infants to begin to discern the roles that different individuals within such interactions play, leading to understanding of communicative intent and the eventual production of intersubjective linguistic constructions (Tomasello, 2003). Thus, the combined achievement of intentional agent understanding and language is proposed to facilitate the process of abstract mental representation by enabling the infant to begin to consider the different perspectives of others and eventually to reflect on their own thought from multiple perspectives (Tomasello, 1999).

These opposing approaches to the development of symbolic functioning make differing predictions about the relationship between linguistic and non-linguistic systems. A domain-specific approach (e.g. Pinker, 1997) predicts that graphic symbolism, symbolic play and language develop independently, thus predicting no concurrent or longitudinal relationships between the three domains. In contrast, the domain-general view of Piaget (1952) predicts that such skills develop in relative synchrony, thus predicting positive relationships between domains both concurrently and over time. Finally, the socio-cultural approach of both Vygotsky $(1962,1978)$ and Tomasello and colleagues (e.g. Tomasello, Kruger \& Ratner, 1993) predicts that language, symbolic play and graphic symbolism develop in a fixed sequence, with language emerging first and predicting other abilities over time.

Various studies investigating the relationship between language and symbolic play have reported a co-occurrence of early language and initial pretend gestures in children below 3 years of age and have been cited as supporting Piaget's (1952) claim that the emergence and growth of language and play are determined by the same underlying cognitive structure. McCune (1995) reported that language and play measures were tightly coupled in infants aged 8-24 months, with developmental milestones in play generally preceding comparable developments in language (see also Ogura, 1991).

Problematically, both McCune (1995) and Ogura (1991) measured play and language by utilizing naturalistic methodologies in which children are presented with a set of objects in the presence of their mother (i.e. in joint activity) (Lewis, Boucher, \& Astell, 1992). As Striano, Tomasello, and Rochat (2001) asserted, such an approach may overestimate children's symbolic play abilities by failing to take into account the influence of participating adults' action models and verbal scripts. Vygotsky (1978) proposed that guidance from a more sophisticated partner can promote children's cognitive growth, with children moving from their actual developmental level to a higher level of potential development across a zone of proximal development. In two experiments investigating the symbolic play of 18- to 36-month-old infants without the provision of adult action models or verbal scripts, Tomasello, Striano, and Rochat (1999) and Striano et al. (2001) found little evidence of true symbolic understanding and production until 26 months of age. This is further supported by research suggesting that, until the third year, children struggle to understand that objects functioning as symbols have a dual status; that 
is, that they are both a concrete objects to be explored and manipulated and an abstract representation standing for something else (Deloache, Pierroutsakos, \& Uttal, 2003).

Failure to take into account the cognitive demands of understanding the dual status of symbolic objects, as well as the influence of social support, has also undermined research into graphic symbolism and its relationship with language. Callaghan, Rochat, MacGillivray, and MacLellan (2004) argued that, as in symbolic play, infants learn to act upon graphic symbols by imitating the referential actions of others in their culture. From a Vygotskian perspective, language is argued to play a pivotal role in mediating early picture functioning (Callaghan \& Rankin, 2002). In a study investigating the role of language support in the emergence of 2- to 4-year-old children's graphic symbol comprehension and production, Callaghan (1999) found that only 3- and 4-year-old children could understand and produce drawings as symbols when the depicted target objects had the same verbal label but were visually distinct. Accordingly, in agreement with Tomasello et al., (1999) without the availability of verbal labels to scaffold their symbolic skills, none of the 2-year-olds performed at levels above chance.

In summary, naturalistic, Piagetian studies such as McCune (1995) support the proposal of a single domain-general representational mechanism, whereas Vygotskian-inspired research that takes into account the effects of social scaffolding illustrates considerable decalage in language, graphic symbolism and symbolic play development. This decalage could be interpreted as indicative of the domain specificity of symbolic functioning (e.g. Fodor, 1983) or as evidence in support of a Vygotskian view that both graphic symbolism and symbolic play emerge and develop from the acquisition of the representational function in language.

The validity of such competing hypotheses can arguably only be sought in the context of research that has investigated the emergence of graphic, language and symbolic play skills in a single study, whilst also attempting to control for the influence of verbal mediation. Only one such study exists. Callaghan and Rankin (2002) assessed 12 children's comprehension and production of language, symbolic play and graphic symbols at monthly intervals from 28-36months and again at 42 months. To consider the possibility that language may contribute to processing in other domains, the researchers used measures that both allowed for and controlled linguistic support. In the graphic tasks, objects were used that had either familiar or unfamiliar labels, and in the symbolic play tasks, the child either played alone for 2 minutes or with their mother for 10 minutes. Children's receptive and expressive language abilities were assessed through the standardized Preschool Language Scale (PSL-3) and by calculating the mean length of the children's five longest utterances (Mean Length of Five Longest Utterances (MLU5)) from the transcripts of the mother/child play sessions. Overall, Callaghan and Rankin (2002) reported results that concur with a domain-general account of symbolic development. Specifically, significant positive correlations were found between comprehension measures across all three symbolic domains. Additionally, the majority of production measures significantly correlated. More notably, the unscaffolded measure of symbolic play production did not correlate with any of the graphic or language production measures, leading Callaghan and Rankin to suggest that children were relying heavily upon their linguistic abilities to improve their performance in the other symbolic domains.

Although Callaghan and Rankin's (2002) study goes some way towards explaining the nature of early symbolic development, further research is needed to support and clarify their findings. This is particularly necessary because of the small scale of their longitudinal research and the fact that the contribution of non-verbal abilities to 
performance in each domain was not considered. Further study of this type is required to shed light upon the role of language in the less well-researched areas of symbolic play and graphic symbolism (Silvestre \& Cambra, 2009) and to address the domain generality/specificity debate in a developmental context, which is also crucial for understanding the end state of adult cognition (Piaget, 1926).

The current research therefore aimed to further examine the relationships between symbol production in graphic, language and symbolic play domains during and between the fourth and the fifth years of childhood. Research conducted by Tomasello et al. (1999) and Callaghan $(1999,2000)$ suggests that this is an important period for symbolic play and graphic symbol production when the mediating effects of language are taken into account. Controlling for the scaffolding influence of language is crucial to ensure that children's graphic and symbolic play abilities are not overestimated. By the fourth year, research suggests that children no longer rely heavily upon language to support their graphic and play development; however, to further reduce this possibility, the non-verbal version of the Test of Pretend Play (ToPP) (Lewis \& Astell, 1997) was utilized, as well as a measure of graphic symbolism where the objects drawn had no conventional verbal labels or a label that was unlikely to be familiar to young children. To achieve accurate and realistic measures of children's abilities within each domain, standardized assessment procedures were used wherever possible.

A lack of concurrent correlations between language, graphic symbolism and symbolic play domains in this study may indicate that although qualitatively similar, such skills do not share a common underlying and determining basis and are therefore domain specific. A domain-general or 'homology through shared origins' account of symbolic development would therefore seem unlikely (Bates, 1979). Longitudinal relationships were also examined between domains from the fourth to the fifth year. Crucially, such relationships can reveal which symbolic abilities predict development in other symbolic domains over time. From a socio-cultural perspective, a 'homology through direct causation model' (Bates, 1979) predicts a developmental sequence in which language predicts symbolic play and graphic symbolism but not vice versa. In contrast, the Piagetian account predicts the presence of relationships between all domains, with symbolic play and graphic symbolism also having a facilitative influence upon language. Previous research conducted by Callaghan and Rankin (2002) supports a domain-general Piagetian account of symbolic development, with positive correlations reported between the majority of domains for both symbolic comprehension and production. With these results and prior research in this area (e.g. McCune, 1995), the hypotheses for the current research were that positive correlations would be found between all symbolic domains, both concurrently and longitudinally.

\section{METHOD}

\section{Participants}

Sixty $(n=60)$ participants between the ages of 3 years to 4 years 1 month (mean age: 3years 6 months) were recruited from ten nurseries in the Stoke-On-Trent and Preston (UK) areas. Parents were asked to provide contact details (a telephone number, e-mail address or home address) if they agreed for their children to take part in a further testing period a year later. The sample was predominantly White and of mixed class, consisting of 34 male and 26 female participants. Overall, 45 parents provided some form of contact information; thus, attempts were made to contact 
all such parents for the longitudinal component. Of these, ten did not respond, one declined to participate and three had moved away from the study catchment area and were unable to take part; thus, the attrition rate for this study was relatively high at $48 \%$. The remaining 31 parents agreed for their children to be re-tested. All 31 participants were tested within 1 month of the relevant target age between the ages of 4 years 1 month and 5 years 1 month (mean age 4 years 6 months). The follow-up sample was similar in composition with the original, made up of 19 male and 12 female participants from mainly White, but mixed class backgrounds. All of the 31 participants completed the testing schedule.

All participants were tested individually by the experimenter using the same measures and procedures outlined in the following text. The order of language, play, graphic and non-verbal tasks was randomized across participants and took on average 2 hours and 10 minutes to complete.

\section{Materials and Procedure}

Symbolic play

Production of symbolic play was assessed using the non-verbal version of the ToPP, in which the availability of linguistic scaffolding is relatively controlled. All play tasks in the ToPP were video recorded and coded at a later date.

\section{The Test of Pretend Play (Lewis \& Astell, 1997)}

The ToPP examines four different aspects of symbolic play, including (i) substitution, (ii) property attribution, (iii) reference to an absent property and (iv) sequential combination of pretend actions. Fifteen different materials are utilized throughout the test, including representational items and toys (a bowl, spoon, teddy and a doll) and non-representational items (a yellow top, a red cloth, a white counter, a black box, a brown stick, a round white tub, a blue cloth, a white plastic reel, a white board, a wooden box and pieces of cotton wool.)

To reduce the linguistic cues available to participants, the non-verbal version of the ToPP was administered according to the standardized procedures set out in the test manual. Instead of specific verbal instruction to carry out a play act, the nonverbal version utilizes gestures, pointing, touching, eye contact, facial expression and short general phrases such as 'show $\mathrm{me}^{\prime}$ to encourage the child to copy a symbolic action that the experimenter has modelled or to elicit original symbolic play. Any spoken language does not relate to the content of a symbolic act but rather serves to attract the child's attention to the play materials or to the action shown by the experimenter. For example, to elicit an original symbolic act, the experimenter encourages the child to play with the materials by placing them near to the child's hands and saying their name. If the child ignores the materials, the experimenter may pick them up and show/pass them to the child and say 'look!'

Each child was initially encouraged to participate in the test by the experimenter stating, 'I have some new toys for us to play with. Can you show me what you can do with them?' Each participant was then guided through the four sections of the test, which examine (i) the child's ability to make reference to an absent object when supported by everyday objects (a bowl and a spoon), (ii) ability to substitute between one and four non-representational items for pretend objects during play with a doll, (iii) ability to make a representational toy (a teddy) refer to an absent object, feel an imagined emotion, pretend to be something else and carry out a scripted sequence of events and (iv) ability of the child alone to pretend to be something else, to refer to an absent object, to attribute an imagined property to oneself and to perform a 
scripted play sequence. Thus, all sections except the first were divided into four individual subsections. For sections 1 and 2, participants were initially presented with a different range of objects and were encouraged to play with them by the experimenter placing the objects near to the child or in their hands. The child was observed playing with the objects, and care was taken not to prompt or cue the child in their activity. Following the test instructions, if an example of original symbolic play was not produced by the child on their own within 4 minutes, the experimenter then modelled a standardized symbolic act with the object, and the child was instructed to copy it by short phrases such as 'your turn now' or 'you show me'. If the child did not imitate the action, the model was repeated on one further occasion. Sections 3 and 4 of the test differed in that a modelled act was produced first within each subsection, followed by an attempt to elicit an original symbolic production. If such a production did not occur, the process was repeated once more with a different modelled act. Two points were awarded for the production of an original symbolic act, but if such an act was not produced, one point was given for successfully copying a modelled act. Although credit is given for imitation as an important foundation of symbolic functioning, points are only allocated for imitating one modelled act within each subsection. The maximum score a child can achieve through imitation alone is 17, compared with a maximum of 34 for original productions. Thus, higher scores should represent a more advanced symbolic ability rather than a general motivation to imitate.

\section{Language Tasks}

Participants' overall language ability was assessed through the third edition of the PSL-3 (Zimmerman, Steiner, \& Pond, 1992), adapted for use in the UK by Boucher and Lewis (1997). A further measure of children's expressive language was the mean length of their five longest utterances (in morphemes) derived from transcripts of 20 minutes of free play that took place between each participant and the first author at times 1 and 2. All free play sessions were video recorded and transcribed by the first author. The content of each play session was determined by the participant's actions and verbal suggestions with the first author following their lead. The first author had spent at least a day in each nursery prior to the play session to ensure that the children felt comfortable to speak and interact in her presence. To attempt to provide continuity of language input across sessions, care was taken to mirror rather than extend the child's verbal language in any communicative exchanges, as well as restricting any verbal prompts made to simple suggestions such as 'what is Teddy going to do now?' Use of a standard set of representational and non-representation materials ensured that play and narrative themes were similar across all sessions (e.g. common reoccurring themes were having a picnic and building a house with toy bricks).

\section{The Preschool Language Scale}

Administration of the PSL-3 followed the standard assessment format and required use of a standardized booklet of pictures and toys. The PSL-3 incorporates both expressive communication and auditory comprehension (AC) components; the order of which was continually counterbalanced for each child. Both the AC and expressive communication subscales assess the semantic and structural aspects of the child's linguistic development, as well as their integrative thinking skills. Specifically, the AC component measures the child's understanding of vocabulary and relational concepts (e.g. being able to identify familiar objects) and comprehension 
of morphological and syntactic markers such as pronouns and negatives. Integrative thinking skills are assessed through understanding of conceptual relationships, such as being able to categorize and compare objects. The child's expressive vocabulary and syntax (e.g. simple and complex sentences, pronouns and inflectional morphology) are tested through picture naming and various elicitation techniques. The child's overall ability to express themselves in a logical way is also assessed through tasks such as describing a procedure and talking about remote events.

\section{Mean Length of Five Longest Utterances}

All children's transcribed utterances were numbered, and the amount of morphemes in each was calculated following a standard approach (Johnson, 2005), ignoring words that were unintelligible, fillers or repetitions (unless these were for emphasis). Within this approach, irregular plurals and past tense verbs (e.g. men and went) and diminutives (e.g. doggie) were only counted as one morpheme. However, words containing the s-plural, -ed past tense and -ing progressive tense markers (e.g. dogs, walked and drawing) were counted as two morphemes, along with contractions of two words such as we've. Exceptions to this rule included does, let's, won't, don't and gonna, which children were assumed to understand as one word and thus were counted as one morpheme.

\section{Graphic Symbolism Task}

Each child was provided with an $\mathrm{HB}$ pencil and A4 paper to complete their drawings. The graphic production task utilized six objects divided into two sets. These were a clacker toy, a wristbells strap, a tinker toy, a frisbee, a tambourine and a sound toy (shown in Figure 1). All items could be drawn using a combination of circles and lines, which constitute the first drawing units or graphic primitives that appear in children's early drawing attempts (Levin \& Bus, 2003). Accordingly, as Callaghan and Rankin (2002) asserted, failure to produce an accurate representation of each object in the task should be interpretable as the result of a symbolic rather than motor production deficiency. To further consider the influence of motor skills, all participants were asked to draw a free picture of anything that they chose before the graphic task began. All participants' free drawings were subsequently assessed by the experimenter to ascertain whether they contained both the circles and lines that could effectively be used to represent the target objects. Overall, only three participants failed to produce drawings containing these graphic units. However, all of these participants went on to successfully depict the target objects in the graphic production task, suggesting they were capable of producing symbolic drawings.

To facilitate equivalent comparison with the composite non-verbal score produced by the ToPP, the test of graphic symbol production also required drawings to be produced either with or without action modelling provided by an adult, which consisted of the experimenter producing a simple picture of the target object (illustrated in Figure 2). As in the ToPP, the beneficial influence of such modelling was considered, with higher scores allocated for unsupported, original productions. Participants were asked to draw three items with modelling and three items without modelling. The objects that were modelled and the order in which the modelled and non-modelled object sets were presented were alternated between six possible combinations across every six participants tested. All objects were presented in front of children on a table, and care was taken not to verbally label them. To prevent the potentially confounding effect of participants manually handling the objects, all children were instructed that they could play with the items after they had completed 
Six objects used in the Graphic Symbolism Task

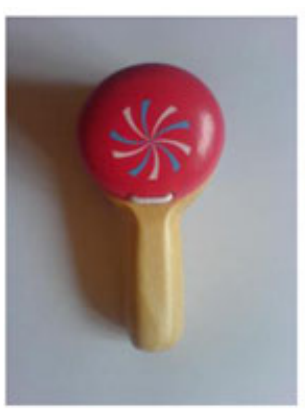

Clacker Toy

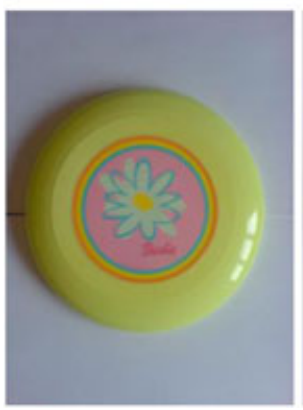

Frisbee

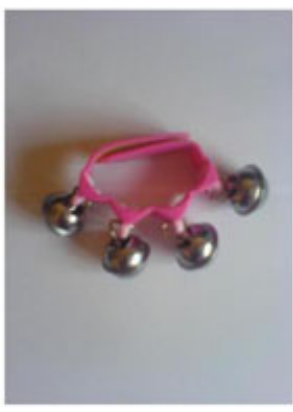

Wristbells Strap

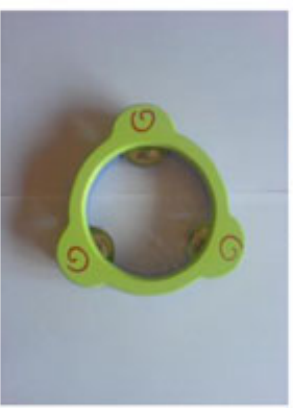

Tambourine

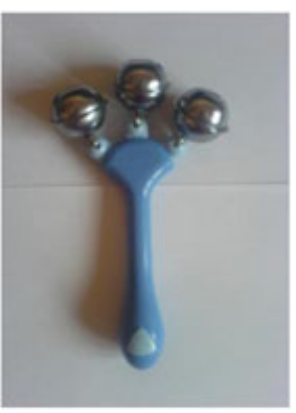

Tinker Toy

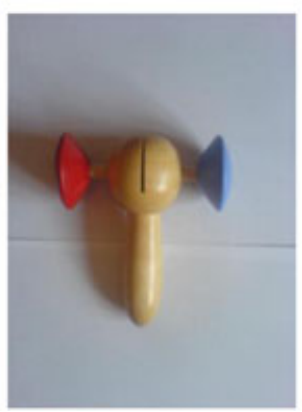

Sound Toy

Figure 1. Six objects used in the graphic symbolism task.

Experimenter's Drawings of the Six Objects used in the Graphic Symbolism Task

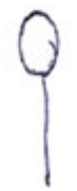

Clacker Toy

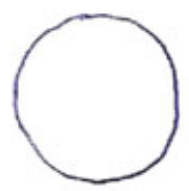

Frisbee

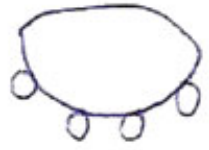

Wristbell Strap

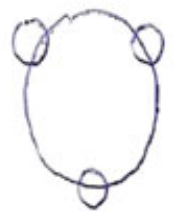

Tambourine

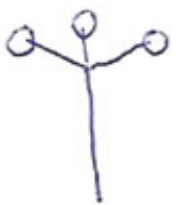

Tinker Toy

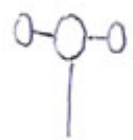

Sound Toy

Figure 2. Experimenter's drawings of the six objects used in the graphic symbolism task. 
their drawing. In the modelling condition, children were requested to watch the experimenter very carefully as they drew the object. The referential relationship between the object and picture produced was also highlighted by the experimenter pointing to their drawing and stating 'this drawing shows this object'. The experimenters' drawing was removed before each participant began their own picture. For both the modelled and unmodelled conditions, participants were given a maximum of 10 minutes to complete their drawings and were instructed to produce the best picture that they could.

\section{Non-verbal Measures}

Participants' non-verbal abilities were assessed through administration of the performance component of the Wechsler Preschool and Primary Scale of Intelligence-Third Edition (WPPSI-III; Weschler, 2002). For children aged up to 4 years, assessment of performance IQ using the WPPSI-III requires completion of two tasks: block design and object assembly. The block design task involves the participant constructing a specific design with coloured blocks from a model of that design built by the experimenter or from a picture. Both model or picture remained in front of the child whilst they performed the task, and each task item had a specified time limit of between 30 and 90 seconds in which the design had to be accurately replicated. The object assembly task involved participants fitting several picture puzzles together in a standard arrangement after watching the experimenter complete them. After completion by the experimenter, each single picture puzzle was disassembled and was given to the child individually to complete as quickly as they could within a time limit of 90 seconds. Each puzzle was scored according to the number of correct junctures that the child achieved between the pieces. The order of tasks was counterbalanced for each participant.

\section{Scoring}

\section{Symbolic play, language and non-verbal measures}

Participants' performances in the ToPP, PSL-3 and WPPSI-III were scored by the experimenter according to standardized guidelines set out in the test instruction manuals. The ranges of possible scores for each test were 0-34 for the ToPP, 10-96 for the PSL-3 and 0-77 for the WPPSI-III.

The same independent rater scored $15 \%$ of the videotaped ToPP sessions at testing points 1 and 2 to obtain inter-rater reliability. Videos were randomly selected for scoring by the experimenter using a basic lottery method. Reliability was acceptable for the ToPP at times 1 (agreement $=78 \%, k=.74$ ) and 2 (agreement $=100 \%, k=1$ ).

\section{Graphic symbolism}

Whether children's pictures constituted effective graphic symbols of the target objects was determined by two independent raters. Raters were presented with all participants' drawings in a random order and were blind to their age, whether the drawing had been modelled and what object the child was attempting to depict. They were then asked to classify each picture as the object they thought the child was intending to represent. Thus, chance level was 0.17 . Initial inter-reliability was high at both times 1 (agreement $=75 \%, k=.70$ ) and 2 (agreement $=91 \%, k=.82$ ); thus, raters were not asked to re-assess decisions upon which they had disagreed. Rater two's categorizations were used for analytic purposes because this individual had greater experience in the research of children's drawings. Following the ToPP scoring 
system, drawings that were coded as successful representations were allocated a score of one if they had been produced after modelling or two if they were produced without imitation. The range of possible scores for this task was 0-12 points.

\section{RESULTS}

\section{Time 1}

Pearson product-moment correlations (one tailed) were conducted to assess the relationship between language, graphic symbolism, symbolic play and non-verbal abilities during the fourth year. Raw scores were used from tests in each domain. The means and variances used to calculate all correlations are shown in Table 1. As hypothesized, Table 1 illustrates that significant positive correlations were found between all measures across the three symbolic domains, except between graphic symbolism and MLU5-assessed language production. Additionally, significant positive relationships were found between non-verbal ability and all language, graphic and play measures.

\section{Regression analyses}

As a number of positive relationships were found between all domains, a series of hierarchal regression analyses were conducted to disentangle these effects. In the first block, all variables from the non-dependent symbolic domains were entered, followed by age and non-verbal abilities in the second block. This approach enabled us to first examine the extent of the relationship between each symbolic domain independent of age and non-verbal intelligence and then scrutinize these relationships further by entering age and non-verbal controls into the equations. Each final model re-apportioned variance to age and non-verbal intelligence if they significantly added to the amount of overall variance explained. Any outliers ( $>3$ standard deviations away from the mean) identified by the initial regression analyses were deleted from the data set, and the analyses were re-performed. Overall, three outliers were

Table 1. Mean overall score and inter-correlations between graphic, play, language and non-verbal performance measures at time $1(n=60)$

\begin{tabular}{|c|c|c|c|c|c|}
\hline & Graphic & ToPP & PSL-3 & MLU5 & WPPSI-III \\
\hline$M$ & 4.85 & 14.7 & 66.82 & 9.33 & 44.27 \\
\hline (SD) & 2.49 & 4.42 & 8.50 & 3.04 & 9.15 \\
\hline \multicolumn{6}{|c|}{ Correlations } \\
\hline \multirow[t]{2}{*}{ Graphic } & & .28 & .34 & .16 & .26 \\
\hline & & $p=.02$ & $p<.001$ & ns & $p=.02$ \\
\hline \multirow[t]{2}{*}{ ToPP } & & & .44 & .48 & .40 \\
\hline & & & $p<.001$ & $p<.001$ & $p<.001$ \\
\hline \multicolumn{2}{|l|}{ PSL-3 } & & & .41 & .55 \\
\hline & & & & $p<.001$ & $p<.001$ \\
\hline \multirow{2}{*}{ MLU5 } & & & & & .37 \\
\hline & & & & & $p<.001$ \\
\hline
\end{tabular}

ToPP $=$ The Test of Pretend Play; PSL-3= Preschool Language Scale; MLU5= Mean Length of Five Longest Utterances; WPPSI-III = Wechsler Preschool and Primary Scale of Intelligence-Third Edition; $\mathrm{SD}=$ standard deviation . 
removed from the analyses of symbolic play and MLU5, respectively, two outliers were deleted from the PSL-3 analysis and one outlier was removed from the graphic symbolism regression.

Results for each of the separate symbolic domains are shown in Tables 2-5. Figure 3 illustrates all significant standardized direct effects found by the regression models. In summary, significant predictive relationships were again found between the majority of symbolic domains, except between symbolic play and graphic symbolism, which approached statistical significance.

\section{Graphic symbolism}

Graphic symbolism was best predicted by a model that included only the symbolic play and language measures $(F(3,58)=4.59, p=.01$; adjusted $R$ squared $=.16)$. The addition of age and non-verbal ability did not have a significant influence upon the amount of variance explained by the regression model.

\section{Symbolic play}

Symbolic play was best predicted by a regression model that included all other symbolic measures, in addition to age and non-verbal ability $(F(5,56)=9.40, p<.001$; adjusted $R$ squared $=.48$ ). Of these measures, language production assessed by MLU5 was the strongest significant predictor $(\beta=.40, p<.001)$. Age was also a significant but less strong predictor of symbolic play $(\beta=.25, p=.04)$.

Table 2. Results of regression analysis examining the influence of language, symbolic play, non-verbal measures and age upon graphic symbolism at time $1(n=59)$

\begin{tabular}{llllll}
\hline & Variable & $B$ & SE $B$ & $\beta$ & Part correlation \\
\hline Step 1 $\left(R^{2}=.20^{* *}\right)$ & MLU5 & -.08 & .12 & $-.09 n s$ & -.08 \\
& PSL-3 & .09 & .04 & $.31^{*}$ & .27 \\
& ToPP & .16 & .08 & $.27 n s$ & .23 \\
\hline
\end{tabular}

MLU5 = Mean Length of Five Longest Utterances; PSL-3 = Preschool Language Scale; ToPP = The Test of Pretend Play; $\mathrm{SE}=$ standard error; $n s=$ not significant.

${ }^{*} p<.05 .{ }^{* *} p<.01$.

Table 3. Results of regression analysis examining the influence of language, graphic symbolism, non-verbal measures and age upon symbolic play at time $1(n=57)$

\begin{tabular}{llllll}
\hline & Variable & $B$ & SE $B$ & $\beta$ & Part correlation \\
\hline Step 1 $\left(R^{2}=.38^{* *}\right)$ & MLU5 & .60 & .16 & $.44^{* *}$ & .40 \\
& PSL-3 & .08 & .06 & $.17 n s$ & .15 \\
& Graphic & .33 & .20 & $.20 n s$ & .18 \\
Step 2 $\left(R^{2}=.48^{* *}\right)$ & MLU5 & .54 & .15 & $.40^{* *}$ & .36 \\
& PSL-3 & .02 & .06 & $.03 n s$ & .02 \\
& Graphic & .23 & .19 & $.14 n s$ & .13 \\
& Age (months) & .26 & .12 & $.25^{*}$ & .21 \\
& WPPSI & .08 & .06 & $.18 n s$ & .13 \\
\hline
\end{tabular}

MLU5 = Mean Length of Five Longest Utterances; PSL-3 = Preschool Language Scale; WPPSI = Wechsler Preschool and Primary Scale of Intelligence; SE = standard error; $n s=$ not significant.

${ }^{*} p<.05$. ${ }^{* *} p<.01$. 
Table 4. Results of regression analysis examining the influence of symbolic play, graphic symbolism, non-verbal measures and age upon MLU5-assessed language production at time $1(n=57)$

\begin{tabular}{llrrrr}
\hline & Variable & $B$ & SE $B$ & $\beta$ & Part correlation \\
\hline Step 1 $\left(R^{2}=.24^{* *}\right)$ & ToPP & .31 & .08 & $.49^{* *}$ & .47 \\
& Graphic & -.02 & .14 & $-.02 n s$ & -.02 \\
Step 2 $\left(R^{2}=.37^{* *}\right)$ & ToPP & .25 & .08 & $.41^{* *}$ & .35 \\
& Graphic & -.09 & .13 & $-.08 n s$ & -.07 \\
& Age (months) & -.14 & .09 & $-.19 n s$ & -.16 \\
& WPPSI & .13 & .04 & $.44^{* *}$ & .36 \\
\hline
\end{tabular}

MLU5 = Mean Length of Five Longest Utterances; ToPP $=$ The Test of Pretend Play; WPPSI $=$ Wechsler Preschool and Primary Scale of Intelligence; SE = standard error; $n s=$ not significant.

$* * p<.01$.

Table 5. Results of regression analysis examining the influence of symbolic play, graphic symbolism, non-verbal measures and age upon PSL-3-assessed language ability at time 1 $(n=58)$

\begin{tabular}{llcccc}
\hline & Variable & $B$ & SE $B$ & $\beta$ & Part correlation \\
\hline Step 1 $\left(R^{2}=.30^{* *}\right)$ & ToPP & .82 & .22 & $.45^{* *}$ & .43 \\
& Graphic & .69 & .38 & $.21 n s$ & .21 \\
Step 2 $\left(R^{2}=.48^{* *}\right)$ & ToPP & .53 & .21 & $.29^{*}$ & .25 \\
& Graphic & .45 & .34 & $.14 n s$ & .13 \\
& Age (months) & -.12 & .25 & $-.06 n s$ & -.05 \\
& WPPSI & .43 & .10 & $.49^{* *}$ & .41 \\
\hline
\end{tabular}

PSL-3 = Preschool Language Scale; ToPP = The Test of Pretend Play; WPPSI $=$ Wechsler Preschool and Primary Scale of Intelligence; SE = standard error; $n s=$ not significant.

${ }^{* *} p<.01{ }^{*} p<.05$.

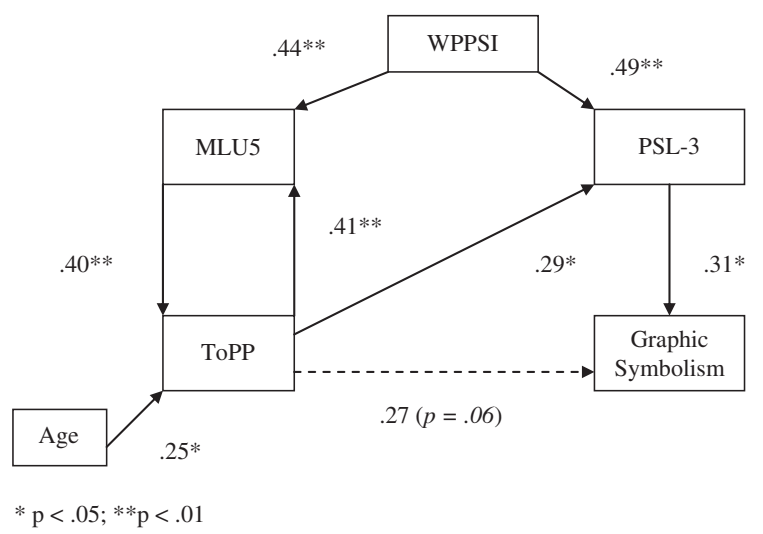

Figure 3. Summary of direct effects from hierarchal multiple regression analyses (standardized coefficients) at time 1.

\section{Language}

MLU5 language production was best explained by a regression model that incorporated all variables, including age and non-verbal ability $(F(4,56)=7.60$, 


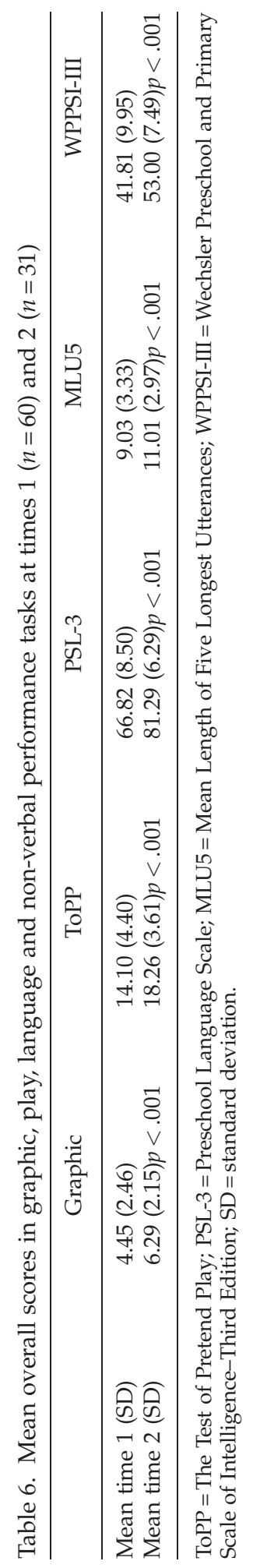


$p<.001$; adjusted $R$ squared $=.32)$. Non-verbal ability was the strongest significant predictor of MLU5 $(\beta=.44, p<.001)$, followed by symbolic play $(\beta=.41, p<.001)$. Similar results were shown for PSL-3 assessed language, which were also best explained by a model including all the predictor variables $(F(4,57)=12.32, p<.001$; adjusted $\mathrm{R}$ squared $=.44)$. Again, non-verbal ability emerged as the strongest predictor $(\beta=.49, p<.001)$, followed by symbolic play $(\beta=.29, p=.02)$.

Figure 3 summarizes the unique relationships between the variables. There were significant relationships between language and symbolic play, and language and graphic symbolism. The relationship between symbolic play and graphic symbolism also approached significance. Symbolic play significantly predicted both PSL-3 and MLU5 measures of language. Graphic symbol ability was significantly influenced by the PSL-3 assessed language measure but did not itself predict abilities in any other symbolic domains.

\section{Longitudinal Analyses}

To assess whether participant's abilities in each symbolic domain improved over time, mean scores in each task at time 1 were compared with mean scores achieved at time 2, using a series of dependent $t$-tests (two tailed) As Table 6 illustrates, significant developmental progression occurred in all tasks.

Temporal correspondences between developing language, symbolic play, graphic symbolism and non-verbal abilities were initially assessed by conducting Pearson product-moment correlations between scores achieved at times 1 and 2 . The results of these analyses are displayed in Table 7.

The initial correlational analyses reveal a significant influence of language in the development of skills in other symbolic domains over time. Specifically, MLU5 during the fourth year significantly predicted symbolic play during the fifth year, as well as graphic symbolism, non-verbal abilities and language measured by the PSL-3. Similarly, PSL-3 assessed language during the fourth year also predicted symbolic play, as well as PSL-3 scores a year later, although it was not significantly predictive of any other measures at time 2 . In contrast to the predictive influence of language over time, neither measure of symbolic play nor graphic symbolism at

Table 7. Inter-correlations between graphic, play, language and non-verbal performance measures from time $1(n=60)$ to $2(n=31)$

\begin{tabular}{lccccc}
\hline Time 1 & Graphic & ToPP & PSL-3 & MLU5 & WPPSI-III \\
\hline Time 2 & & & & & \\
Graphic & .04 & .12 & .25 & .46 & .47 \\
& $n s$ & $n s$ & $n s$ & $p=.01$ & $p<.001$ \\
ToPP & .22 & .27 & .60 & .45 & .32 \\
& $n s$ & $n s$ & $p<.001$ & $p=.01$ & $p=.04$ \\
PSL-3 & .30 & .23 & .83 & .60 & .58 \\
& $n s$ & $n s$ & $p<.001$ & $p<.001$ & $p<.001$ \\
MLU5 & .18 & .15 & .26 & .17 & -.08 \\
& $n s$ & $n s$ & $p=.08$ & $n s$ & .75 \\
WPPSI-III & .40 & .40 & .25 & .57 & .77 \\
& $p=.01$ & $p=.01$ & $n s$ & $p<.001$ & $p<.001$ \\
\hline
\end{tabular}

ToPP $=$ The Test of Pretend Play; PSL-3= Preschool Language Scale; MLU5= Mean Length of Five Longest Utterances; WPPSI-III = Wechsler Preschool and Primary Scale of Intelligence-Third Edition; $n s=$ not significant. 
time 1 were found to predict language or each other a year later. These measures did, however, predict non-verbal abilities during the fifth year. Similarly, non-verbal abilities at time 1 also predicted graphic symbolism and symbolic play performance at time 2, in addition to PSL-3-assessed language and non-verbal abilities.

To further investigate these predictive relationships, a series of hierarchal regression analyses were conducted. Although the sample size at time 2 was relatively small $(n=31)$, previous longitudinal studies have successfully utilized such multivariate analyses to investigate developmental relationships with an equivalent sample size and number of predictor variables (e.g. Shore, O'Connell \& Bates, 1984; Shore, 1986). Following the procedure utilized for time 1 data, for each dependent variable at time 2 (e.g. graphic symbolism), all other non-dependent symbolic measures at time 1 were entered as predictor variables in the first step of the regression model (e.g. ToPP, PSL-3 and MLU5) followed by time 1 age and non-verbal ability in a second step. One outlier was identified and removed from the analysis of PSL-3 at time 2, and the regression was re-performed. Results for each of the symbolic measures at time 2 are discussed individually in the following text and are displayed in Tables 8-11.

\section{Graphic symbolism}

Graphic symbolism at time 2 was best predicted by a model that included only time 1 symbolic play and language measures $(F(3,30)=2.95, p=.05$; adjusted $R$ squared $=.16$ ). The addition of age and non-verbal ability did not have a significant influence upon the amount of variance explained by the regression model. Overall, only MLU5 functioned as a significant predictor of graphic symbolism at time 2 $(\beta=.61, p=.02)$.

Table 8. Results of regression analysis examining the influence of language, symbolic play, non-verbal measures and age at time 1 upon graphic symbolism at time $2(n=31)$

\begin{tabular}{lllccc}
\hline & Variable & $B$ & SE $B$ & $\beta$ & Part correlation \\
\hline Step 1 $\left(R^{2}=.50^{*}\right)$ & MLU5 & .40 & .15 & $.61^{*}$ & .43 \\
& PSL-3 & -.00 & .04 & -.01 ns & -.01 \\
& ToPP & -.12 & .10 & $-25 n s$ & -.20 \\
\hline
\end{tabular}

MLU5 = Mean Length of Five Longest Utterances; PSL-3 = Preschool Language Scale; ToPP = The Test of Pretend Play; $\mathrm{SE}=$ standard error; $n s=$ not significant.

$* p<.05$.

Table 9. Results of regression analysis examining the influence of language, graphic symbolism, non-verbal measures and age at time 1 upon symbolic play at time $2(n=31)$

\begin{tabular}{llcccc}
\hline & Variable & $B$ & SE $B$ & $\beta$ & Part correlation \\
\hline Step 1 $\left(R^{2}=.37^{*}\right)$ & MLU5 & .18 & .22 & $.19 n s$ & .13 \\
& PSL-3 & .18 & .07 & $.52^{*}$ & .41 \\
& Graphic & -.10 & .26 & $-.07 n s$ & -.06 \\
\hline
\end{tabular}

MLU5 = Mean Length of Five Longest Utterances; PSL-3= Preschool Language Scale; SE= standard error; $n s=$ not significant.

$* p<.05$. 
Table 10. Results of regression analysis examining the influence of symbolic play, graphic symbolism, non-verbal measures and age at time 1 upon PSL-3 assessed language ability at time $2(n=30)$

\begin{tabular}{llrrrr}
\hline & \multicolumn{1}{c}{ Variable } & $B$ & SE $B$ & $\beta$ & Part correlation \\
\hline Step 1 $\left(R^{2}=.09 n s\right)$ & ToPP & .15 & .31 & $.10 n s$ & .20 \\
& Graphic & .61 & .55 & $.24 n s$ & .08 \\
Step 2 $\left(R^{2}=.32^{*}\right)$ & ToPP & -.15 & .30 & $-.10 n s$ & -.08 \\
& Graphic & .33 & .51 & $.13 n s$ & .12 \\
& Age (months) & .01 & .30 & $.00 n s$ & .00 \\
& WPPSI & .35 & .12 & $.55^{*}$ & .47 \\
\hline
\end{tabular}

PSL-3 = Preschool Language Scale; ToPP = The Test of Pretend Play; WPPSI $=$ Wechsler Preschool and Primary Scale of Intelligence; $\mathrm{SE}=$ standard error; $n s=$ not significant. ${ }^{*} p<.05$.

Table 11. Results of regression analysis examining the influence of symbolic play, graphic symbolism, non-verbal measures and age at time 1 upon MLU5-assessed language production at time $2(n=31)$

\begin{tabular}{llcccc}
\hline & \multicolumn{1}{c}{ Variable } & $B$ & SE $B$ & $\beta$ & Part correlation \\
\hline Step 1 $\left(R^{2}=.04 n s\right)$ & ToPP & .05 & .15 & $.07 n s$ & .06 \\
& Graphic & .17 & .27 & $.14 n s$ & .12 \\
Step 2 $\left(R^{2}=.08 n s\right)$ & ToPP & .11 & .16 & $.16 n s$ & .13 \\
& Graphic & .23 & .28 & $.19 n \mathrm{~s}$ & .15 \\
& Age (months) & -.00 & .17 & $-.00 n s$ & -.00 \\
& WPPSI & -.07 & .07 & $-.24 n \mathrm{~ns}$ & -.20 \\
\hline
\end{tabular}

MLU5 $=$ Mean Length of Five Longest Utterances; ToPP $=$ The Test of Pretend Play; WPPSI $=$ Wechsler Preschool and Primary Scale of Intelligence; SE = standard error; $n s=$ not significant.

\section{Symbolic play}

Similarly, symbolic play at time 2 was also best predicted by a model that included only the graphic and language measures at time $1(F(3,30)=5.29, p=.01$; adjusted $\mathrm{R}$ squared $=.37$ ). Overall, only language assessed by PSL-3 at time 1 accounted for significant variance in symbolic play at time $2(\beta=.41, p=.01)$.

\section{Language}

PSL-3 assessed language at time 2 was best explained by a regression model that included all the predictor variables at time $1(F(4,30)=3.10, p=.03$; adjusted $R$ squared $=.22)$. However, only non-verbal abilities emerged as a significant predictor $(\beta=.47, p=.01)$. In contrast, neither of the regression models significantly predicted MLU5 performance at time 2 .

Figure 4 summarises the significant predictive relationships found by the regression analyses from the fourth to the fifth year. In contrast to the initial research hypotheses, the majority of measures did not have significant predictive validity over time. Specifically, in accordance with the initial correlational analyses, no significant predictive relationships were found between the graphic symbolism and symbolic play measures at time 1 and any other symbolic measures at time 2. Indeed, the only significant predictor of language (as measured by the PSL-3) was 


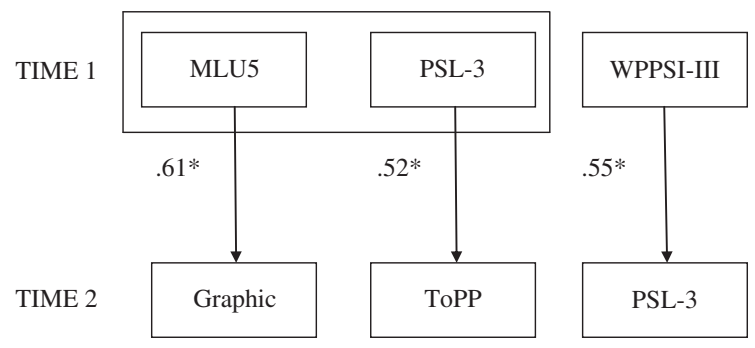

Figure 4. Summary of direct effects from hierarchal multiple regression analyses (standardized coefficients) from time 1 to $2(n=31)$.

participant's non-verbal abilities at time 1. However, again, both graphic symbolism and symbolic play during the fifth year were significantly predicted by linguistic abilities (either PSL-3 or MLU5) a year earlier.

\section{DISCUSSION}

The current study aimed to investigate the under-researched relationships between children's developing language, graphic symbolism and symbolic play skills during and between the fourth and the fifth years of life. Utilizing a short-term longitudinal design and attempting to control for linguistic scaffolding and the influence of nonverbal abilities, this study represents an advance upon previous research within this area (e.g. Callaghan \& Rankin, 2002) and provides a suggestive account of how symbolic development within these domains might proceed and change over time.

The results collated during the fourth year in the first testing period of this study suggest that children's graphic, language and symbolic play skills are inter-related and develop in parallel at this time. Such results are consistent with those reported by Callaghan and Rankin (2002), although the relationships between the symbolic domains in this study largely remained significant even when the influence of children's chronological age and non-verbal abilities was taken into account and when the potential for children to verbally scaffold their performance in the graphic and symbolic play tasks was minimized. Accordingly, the associations found between symbolic domains in this study are less open to the criticism that children's competence in the symbolic play and graphic symbolism tasks was overestimated because of reliance upon language. Although the possibility that children relied upon their private, inner speech in such tasks cannot be discounted (Slobin, 1996), the significant relationships found between the majority of symbolic domains at this time indicate support for a Piagetian account of symbolic functioning in which performance in all symbolic domains (both linguistic and non-linguistic) develops equivalently and relatively simultaneously as a result of being driven by a single, domain-general representational mechanism.

The suggestion that representational principles are shared across both cognitive and linguistic domains is relatively contentious but does mirror a recent trend in the discipline of Psychology away from a conception of the mind and cognition as modular, particularly in the areas of language acquisition and social understanding (Fernyhough, 2008). In particular, the domain-general pattern of associations exhibited during the fourth year of this study may reflect children's emerging metarepresentational capacity (Perner, 1991). Various theorists have described models of 
children's representational development that support this viewpoint (e.g. Leslie, 1987; Suddendorf, 1997). These are similar in proposing developmental progression from primary representations (on the basis of early perceptual experience) towards tertiary representations involving advanced understanding and prediction of mental states. Achievement of symbolism is postulated as intermediate to these stages, with pictures, language and pretence utilizing secondary representations that enable the child not only to perceive and represent the world but also to begin to think about, interpret and reflect upon their own actions, desires and intentions as well as those of others.

The results collected during the second testing period in this study suggest that information within different symbolic domains may not be continually processed in a domain-general manner beyond the fourth year. Longitudinal analyses in this study found no predictive relationships between either symbolic play or graphic symbolism in the fourth year and language in the fifth year. Rather, only language predicted development in these other domains over time. Such results may be interpreted to suggest that an initial domain-general type capacity to process representational stimuli exists until around the fourth year, after which language takes over the role of structuring and guiding development in other symbolic domains, potentially through a process akin to representational redescription (Karmiloff-Smith, 1992).

The idea that language becomes the dominant symbolic system between the fourth and the fifth years supports Vygotskian theory (Vygotsky, 1962, 1978), which proposes that language has a central role both in structuring and mediating the development of skills in other representational abilities, particularly in symbolic play and graphic symbolism. An overall emergent structuring role for language may be explainable as a result of its gradual internalization during early childhood. Although the child's initial acquisition of language may serve primarily social communicative purposes (Abdulrahman, Fernyhough, \& Meins, 2006), research suggests that by 5 years of age, language has become partially internalized to develop into private speech, which augments pre-existing cognitive capacities by allowing the direction, planning and self-regulation of behaviour (Winsler \& Naglieri, 2003). Although private speech may still be spoken aloud during the fifth year, the gradual process of internalization is likely to have fundamentally altered the child's thought processes, offering a means of self reflection and regulation, and a tool to facilitate shifts in perspective taking (Deacon, 1997). Ultimately, private (and eventually inner) speech may operate as a form of cognition in itself, which mediates development in other representational domains at a relatively unconscious and implicit level. Although language may influence and support representational competence in graphic symbolism and symbolic play during the first years of life, it is foreseeable that internalization greatly facilitates this process, allowing language to take the guiding constructive role that Vygotsky $(1962,1978)$ and proponents of the socio-cultural approach have suggested (see also Nelson, 2007).

In contrast to the longitudinal relationships found between language and other symbolic domains in this study, neither the symbolic play nor graphic symbolism tasks predicted children's linguistic knowledge over time. Accordingly, it seems that during this preschool period, symbolic play and graphic symbolism may not offer a window through which children's future linguistic competence can be assessed, arguably because language now proceeds and largely structures development in these domains. However, this is not to say that such tasks would not have predictive validity or offer a means to develop skills necessary for language earlier in life, prior to the shift towards verbal mediation. One limitation of the current research is that the results are specific to the period studied (i.e. from the fourth to the fifth year). Although socio-cultural theories highlight the importance of this period to the 
development of representational competence (e.g. Tomasello et al., 1999), further research is required to study the relationships between representational domains (both concurrently and predictively) at different stages of development.

The interpretation of domain generality followed by a structuring role for language is suggested by the broad pattern of relationships found in the current research. However, there was some inconsistency in associations relating to the two language measures (PSL-3 and MLU5, respectively). For example, over time, each language measure was only predictive of either symbolic play or graphic symbolism. One possible explanation for this discrepancy is that whereas the PSL-3 measure incorporated both aspects of language comprehension and production, MLU5 was solely a measure of expressive language ability. Research has shown that expressive language has a stronger relationship with symbolic play than language production (Lewis, Boucher, Lupton, \& Watson, 2000), but there is limited research considering the effect of different components of language upon graphic symbolism. The small sample size of this study and the large number of measures did not permit separate analyses using individual components of the PSL-3 scale, but this should be considered in future research.

To introduce such additional measures, a larger sample size would be necessary, and thus, future research should address the relatively high attrition rate that was encountered in the current study. Longitudinal research is crucial to document and interpret changes between different symbolic skills over time; however, attrition can lead to loss of statistical power as well as sample bias that may reduce the generalizability of findings (Burton, Laurie, \& Lynn, 2006). The composition of time 2 sample in the present research was similar to that at time 1 with respect to the age, sex and ethnicity of participants. However, it is possible that the families who refused to provide contact details for follow-up study may have differed with respect to other variables such socio-economic status. Although systematic drop out according to familial and social variables does not necessarily influence the validity of predictive correlations (e.g. Wolke et al., 2009), future research should collect more identifying information about participants at first contact so that it is possible to attempt to quantify the amount of error introduced by attrition (Loeber \& Farrington, 1994).

Overall, the results of the current study may be cautiously interpreted to suggest an initial domain-general account of symbolic development during the fourth year, after which language begins to mediate non-verbal cognitive processes as a result of its gradual internalization (Vygotsky, 1962, 1978). A possible objection to this interpretation is that, according to the modular, domain-specific account of development, verbal mediation may occur because language acts as a code through which other cognitive processes are reflected upon within a central processing system (Fodor, 1983). Although this is possible, such a domain-specific account does not predict the integrated pattern of results observed at time 1 during this research, where all domains were inter-related. Although it could be argued that performance in many domains correlates during early childhood, such correlations were not found across developmental time in this study, where only language predicted development in the other non-verbal domains longitudinally. Such results therefore seem most consistent with a socially mediated Vygotskian-inspired account of development. Cross-cultural research is required to verify the structuring role of language reported in the current research, as the use and prominence of verbal and non-verbal symbols during children's early social interactions vary worldwide (e.g. Brown, 2001). Recent research by Callaghan et al. (2011) also suggests that the development of graphic symbolism and symbolic play are particularly influenced by the specific learning experiences that a child encounters. Therefore, 
cross-cultural replication is essential to determine whether the relationships reported here are largely a function of specific socialization and parenting practices rather than being driven by an underlying symbolic mechanism.

\section{REFERENCES}

Abdulrahman, S. A., Fernyhough, C., \& Meins, E. (2006). Socio-cultural influences on the development of verbal mediation: Private speech and phonological recoding in Saudi Arabian and British samples. Developmental Psychology, 42(1), 117-131.

Barrett, H. C., \& Kurzban, R. (2006). Modularity in cognition: Framing the debate. Psychological Review, 113(3), 628-647.

Bates, E. (1979). On the evolution and development of symbols. In E. Bates (Ed.), The emergence of symbols: Cognition and communication in infancy (pp. 33-68). New York: Academic Press.

Boucher, J., \& Lewis, V (1997). The Pre-School Language Scale-3 UK edition. UK: The Psychological Corporation Limited.

Bornstein, M. B., \& Tamis-LeMonda, C. S. (1995). Parent-child symbolic play: three theories in search of an effect Developmental Review, 15, 382-400.

Braswell, G. S. (2006). Socio-cultural contexts for the early development of semiotic production. Psychological Bulletin, 132(6), 877-894.

Brown, P. (2001). Learning to talk about motion UP and DOWN in Tzeltal: Is there a language-specific bias for verb learning? In M. Bowerman, \& S. C. Levinson (Eds.), Language acquisition and conceptual development (pp. 512-543). Cambridge: Cambridge University Press.

Burton, J., Laurie, H., \& Lynn, P. (2006). The long-term effectiveness of refusal conversion procedures on longitudinal surveys. Journal of the Royal Statistical Society, 169(3), 459-478.

Callaghan, T. C. (1999). Early understanding and production of graphic symbols. Child Development, 60, 381-398.

Callaghan, T. C. (2000). Factors affecting children's graphic symbol use in the third year: Language, similarity and iconicity. Cognitive Development, 15, 185-214.

Callaghan, T. C., \& Rankin, M. P. (2002). Emergence of graphic symbol functioning and the question of domain specificity: A longitudinal training study. Child Development, 73(2), 359-376.

Callaghan, T. C., Moll, H., Rakoczy, H., Warneken, F., Liszkowski, U., Behne, T., \& Tomasello, M. (2011). Early social cognition in three cultural contexts. Monographs of the Society for Research in Child Development, 76(2), 1-142.

Callaghan, T. C., Rochat, P., MacGillivray, T., \& MacLellan, C. (2004). Modelling referential actions in 6- to 18-month old infants: A precursor to symbolic understanding. Child Development, 75(6), 1733-1744.

Carpenter, M., Nagell, K., \& Tomasello, M. (1998). Social cognition, joint attention, and communicative competence from 9 to 15 months of age. Monographs of the Society for Research in Child Development, 63.

Chomsky, N. (1957). Syntactic structures. The Hague: Mouton.

D'Souza, D., \& Karmiloff-Smith, A. (2011). When modularization fails to occur: A developmental perspective. Cognitive Neuropsychology, 28(3 \& 4), 276-287.

Deacon, T. W. (1997). The symbolic species: The co-evolution of language and the brain. New York: Norton.

Deloache, J. S., Pierroutsakos, S. L., \& Uttal, D. H. (2003). The origins of pictorial competence. Current Directions in Psychological Science, 12(4), 114-118.

Fernyhough, C. (2008). Getting Vygotskian about theory of mind: Mediation, dialogue, and the development of social understanding. Developmental Review, 28, 225-262.

Fodor, A. J. (1983). Modularity of mind. Cambridge, MA: MIT Press.

Gopnick, A., \& Meltzoff, A.N. (1992). Categorization and naming: Basic level sorting in eighteen-month-olds and its relation to language. Child Development, 63, 1091-1103.

Johnson, B.W. (2005) Mean length of utterance (MLU) http://www.clas.ufl.edu/users/ bwjohn/4004/Materials/MLU.htm Accessed 04.03.2006. 
Karmiloff-Smith, A. (1992). Beyond modularity: A developmental perspective on cognitive science. Cambridge, MA: MIT Press.

Karmiloff-Smith, A. (2009). Nativism versus neuroconstructivism: Rethinking the study of developmental disorders. Developmental Psychology, 45(1), 56-63.

Karmiloff-Smith, A. (2011). The importance of tracing cross-syndrome/cross-domain developmental trajectories. Paper presented at the BPS Annual Conference, Glasgow, UK.

Leslie, A. (1987). Pretence and representation in infancy: The origin of 'theory of mind'. Psychological Review, 94, 412-26.

Levin, I., \& Bus, A. G. (2003). How is emergent writing based on drawing? Analyses of children's products and their sorting by children and mothers. Developmental Psychology, 39(5), 891-905.

Lewis, V., \& Astell, A. (1997). The Test of Pretend Play. London: The Psychological Corporation Limited.

Lewis, V., Boucher, J., \& Astell, A. (1992). The assessment of symbolic play in young children: A prototype test. European Journal of Disorders of Communications, 27, 231-245.

Lewis, V., Boucher, J., Lupton, L., \& Watson, S. (2000). Relationships between symbolic play, functional play, verbal and non-verbal ability in young children. International Journal of Language E Communication Disorders, 35(1), 117-127.

Loeber, R., \& Farrington, D. P. (1994). Problems and solutions in longitudinal and experimental treatment studies of child psychopathology and delinquency. Journal of Consulting and Clinical Psychology, 62, 887-900.

McCune, L. (1995). A normative study of representational play at the transition to language. Developmental Psychology, 31(2), 198-206.

McCune, L. (2008). How children learn to learn words: Dynamic systems in development and action. New York: Oxford University Press.

Nelson, K. (2007). Young minds in social worlds. Cambridge, MA: Harvard University Press.

Ogura, T. (1991). A longitudinal study of the relationship between early language development and play development. Journal of Child Language, 18, 273-294.

Perner, J. (1991). Understanding the representational mind. Cambridge, MA: MIT Press.

Piaget, J. (1926). The language and thought of the child. London: UK: Kegan Paul, Trench, Trübner \& Co.

Piaget, J. (1952). The origins of intelligence in children. New York: Norton.

Pinker, S. (1997). How the mind works. New York: Norton.

Shore, C. (1986). Combinatorial play, conceptual development and early multi-word speech. Developmental Psychology, 22(2), 184-190.

Shore, C., O'Connell, B., \& Bates, E. (1984). First sentences in language and symbolic play. Developmental Psychology, 20(5), 872-880.

Silvestre, N., \& Cambra, C. (2009). The relationship between drawing and oral language in deaf students aged three to five. European Journal of Psychology of Education, XXIV(1), 3-15.

Slobin, D. I. (1996). From 'thought and language' to 'thinking for speaking'. In J. J. Gumperz, \& S. C. Levinson (Eds.), Rethinking linguistic relativity (pp. 70-96). Cambridge: Cambridge University Press.

Stein, B. E., \& Stanford, T. R. (2008). Multisensory integration: Current issues from the perspective of the single neuron. Nature Reviews Neuroscience, 9, 255-266.

Striano, T., Tomasello, M., \& Rochat, P. (2001). Social and object support for early symbolic play. Developmental Science, 4(4), 442-455.

Suddendorf, T. (1997). The rise of the metamind. Retrieved June 25th, 2012, from http:// cogprints.org $/ 732 / 1 /$ metamind $3 . h t m l$

Tomasello, M. (1999). The cultural origins of human cognition. Cambridge, MA: Harvard University Press.

Tomasello, M. (2003). The key is social cognition. In Gentner, D, \& Goldin-Meadow, S (Eds.), Language in mind: Advances in the study of language and thought (pp. 57-58). London, England: The MIT Press.

Tomasello, M., Kruger, A. C., \& Ratner, H. H. (1993). Cultural Learning. Behavioural and Brain Sciences, 16, 495-552.

Tomasello, M., Striano, T., \& Rochat, P. (1999). Do young children use objects as symbols? British Journal of Developmental Psychology, 17, 563-584. 
Vygotsky, L. (1962). Thought and language. Cambridge, MA: MIT Press.

Vygotsky, L. (1978). Mind in society: The development of higher psychological processes. Cambridge, MA: Harvard University Press.

Weschler, D. (2002). The Weschler Pre-school and primary scale of intelligence 3rd Edition. London: Harcourt Assessment.

Winsler, A., \& Naglieri, J. (2003). Overt and covert verbal problem-solving strategies: Developmental trends in use, awareness, and relations with task performance in children aged 5 to 17. Child Development, 74, 659-678.

Wolke, D., Waylen, A., Samara, M., Steer, C., Goodman, R., Ford, T, \& Lamberts, K. (2009). Selective drop out in longitudinal studies and non-biased prediction of behaviour disorders. The British Journal of Psychiatry, 195, 249-256.

Zimmerman, I. L., Steiner, V. G., \& Pond, R. E. (1992). Preschool Language Scale 3rd Edition. San Antonio, TX: The Psychological Corporation. 